V Kumar, B Ghosh, UK Raina and N Goel

Guru Nanak Eye Centre, Maulana Azad Medical

College, New Delhi, India

E-mail: drvinod_agg@yahoo.com

This article has not been presented earlier

Eye (2009) 23, 2122-2123; doi:10.1038/eye.2008.416;

published online 16 January 2009

Sir

\section{Reply to Dr Kumar et al}

We thank Dr Kumar and his associates for their interest in our recent study entitled 'Subthreshold diode micropulse panretinal photocoagulation for proliferative diabetic retinopathy' and for the major concerns they have regarding the study.

Low intensity/high density subthreshold diode micropulse panretinal photocoagulation (SDM PRP) is a laser procedure that allows the management of patients with proliferative and preproliferative diabetic retinopathy without harming the retina or visual function. The desired clinical effect is obtained with low intensity laser applications that do not produce a visible intraoperative burn end point or thermal lesions detectable at any time postoperatively either by clinical examination, fundus photography, fluorescein angiography, or time-domain optical coherence tomography (OCT) as reported by Luttrull et al ${ }^{1-3}$; or by fundus autofluorescence photography, indocyanine green angiography, or fourier-domain OCT (JKL, unpublished data). ${ }^{1-3}$ In the absence of iatrogenic thermal retinal damage, no complications, side effects, or inflammatory reaction of any kind are observed.

Dr Kumar points out that thermal retinal ablation to decrease angiogenic stimuli and improve retinal oxygenation is a widely accepted hypothesis proposed to explain the action of conventional photocoagulation. ${ }^{4}$ However, we remember that thermal retinal destruction has never been shown to be therapeutically necessary. Our results, documenting effective treatment in the complete absence of laser-induced retinal damage counter the claim that tissue ablation is necessary for effective treatment. ${ }^{1-3}$ Thus, by exclusion, we believe that high density/low intensity SDM for both diabetic macular oedema and proliferative retinopathy operates by the same mechanism, that is, by inducing the exposed and affected, but unharmed, RPE cell to alter its expression of key cytokines in a way which is clinically advantageous. . $^{1,3,5}$

We do not use the titration approach enquired by Dr Kumar as reports from studies employing such titration approaches document a high incidence of retinal burns, which may not appear clinically until sometime after treatment. ${ }^{6-8}$ Alteration of SDM parameters based on retinal thickness is unnecessary due to the excellent retinal penetration and minimal scatter of the $810 \mathrm{~nm}$ wavelength. ${ }^{9}$ However, the primary author's 9 years of clinical experience using SDM as the exclusive laser modality for treatment of retinal vascular disease has taught him that certain alterations in treatment parameters based on fundus pigmentation are necessary to minimize the risk of inadvertent burns, as reported by Luttrull et al. ${ }^{1-3}$ We agree with Dr Kumar that pain thresholds are subjective and widely variable. However, the pain threshold with SDM PRP is much lower than the visible burn threshold, in contradistinction to conventional PRP. Thus, we find that patients' pain sensation can provide helpful feedback in the absence of a visible treatment end point. We believe that the wide therapeutic window of SDM permits us this welcome accommodation to patient comfort. ${ }^{1,3}$

To date, all reports of various approaches to SDM for treatment of retinal vascular disease describe clinical effectiveness comparable to conventional photocoagulation with less retinal injury. We have reported effective SDM without any retinal injury at all. These are substantive reasons to pursue further study. We thank Dr Kumar and his associates for their pertinent questions and the Editor for this opportunity to respond.

\section{References}

1 Luttrull JK, Musch DC, Mainster MA. Subthreshold diode micropulse photocoagulation for the treatment of clinically significant diabetic macular edema. Br J Ophthalmol 2005; 89: 74-80.

2 Luttrull JK, Spink CJ. Serial optical coherence tomography of subthreshold diode micropulse photocoagulation for diabetic macular edema. Ophthalmic Surg Lasers Imaging 2006; 37: 370-377.

3 Luttrull JK, Musch DC, Spink CJ. Subthreshold diode micropulse pan retinal photocoagulation for proliferative diabetic retinopathy. Eye 2008; 22: 607-612.

4 Olk RJ, Lee CM. Diabetic Retinopathy: Practical Management. J.B.Lippincot company: Philadelphia, 199393.

5 Flaxel C, Bradle J, Acott T, Samples JR. Retinal pigment epithelium produces matrix metalloproteinases after laser treatment. Retina 2007; 27: 629-634.

6 Laursen ML, Moeller F, Sander B, Sjoelie AK. Subthreshold micropulse diode laser treatment in diabetic macular oedema. Br J Ophthalmol 2004; 88: 1173-1179.

7 Bhagat N, Zarbin MA. Diode subthreshold micropulse laser for diabetic macular edema. Retinal Physician 2006; 3: 53-56.

8 Sivaprasad S, Chong V, Cunha-Vaz JG, Faria de Ahreu, Rosa A, Nunes $\mathrm{S}$ et al. Prospective randomized controlled trial comparing subthreshold micropulse diode laser photocoagulation and conventional green laser for clinically significant diabetic macular edema. Br J Ophthalmol 2008; 92, [e-pub ahead of print].

9 Moorman CM, Hamilton AMP. Clinical applications of the MicroPulse diode laser. Eye 1999; 13: 145-150.

JK Luttrull, D Musch and C Spink

Private practice, Ventura, CA, USA

E-mail: jkluttrull@aol.com

Eye (2009) 23, 2123; doi:10.1038/eye.2008.418; published online 16 January 2009 